Academic Platform Journal of Engineering and Science

\title{
Endüstriyel Delme Artığı ile Üretilmiş Cam Elyaf Takviyeli Çimento Bazlı Kompozitlerin Mekanik Özellikleri
}

\author{
${ }^{* 1}$ Yusuf Arslan, ${ }^{2}$ Sadik Alper Yıldizel \\ ${ }^{1}$ Düzce Üniversitesi, Düzce Meslek Yüksekokulu, Düzce \\ yusufarslan@duzce.edu.tr, \\ ${ }^{2}$ Karamanoğlu Mehmetbey Üniversitesi, Mühendislik Fakültesi, Karaman \\ sayildizel@kmu.edu.tr,
}

Araştırma Makalesi

Geliş Tarihi: 29.08.2018

Kabul Tarihi: 15.03.2019

$\ddot{O} \mathbf{z}$

$\mathrm{Bu}$ çalışmada endüstriyel delme artıkları ile üretilmiş cam elyaf takviyeli betonların mekanik performansı ele alınmıştır. Çapları $5 \mathrm{~mm}$ ve $7 \mathrm{~mm}$ olan iki tür zımba ile delme artığı kompozit üretiminde kullanılmıştır. Cam elyaflar ağılıkça \%3 olarak, delme artıkları ise yine ağırıkça $\% 1, \% 1,5$ ve $\% 2$ olarak kompozit karışımlarına eklenmiştir. Üretilen numuneler üzerinde basınç, çekme dayanımları ve büzülme testleri gerçekleştirilmiştir. Ayrıca, donma ve çözünme etkisi de incelenmiştir. Çalışma sonuçlarına göre zımba ile delme artı̆̆ının ağılıkça \%1,5 oranında kullanılmasının kompozitlerin basınç ve çekme gerilmeleri özelliklerini iyileştirdiği ortaya çıkmıştır. Büzülme davranışı incelendiğinde ise ağılıkça \%2 oranında delme artığı kullanılmasının bu davranış altındaki etkileri azalttığı görüşmüştür.

Anahtar Kelimeler: Delme artığı, çimento bazlı kompozit, cam elyaf

\section{Mechanical Performances of Glass Fiber Reinforced Cementitious Composites Made with Punching Scrap}

\author{
*1 Yusuf Arslan, ${ }^{2}$ Sadık Alper Yıldizel \\ ${ }^{1}$ Duzce University, Duzce Vocational School, Duzce \\ yusufarslan@duzce.edu.tr \\ ${ }^{2}$ Karamanoğlu Mehmetbey University, Engineering Faculty, Karaman \\ sayildizel@kmu.edu.tr
}

\begin{abstract}
This paper deals with the mechanical performances of glass fiber reinforced cementitious composites made with industrial punching scrap. Two types of scraps with diameters of $5 \mathrm{~mm}$ and $7 \mathrm{~mm}$ were used in the production of cementitious composite. The glass fibers were added at the ratio of $3 \%$ by weight, and scrap were mixed with the weight ratios of $1 \%, 1.5 \%$ and $2 \%$. Pressure, flexural strength, and shrinkage tests were carried out on the produced samples. In addition, freezing and thawing effects were also investigated. According to the results of the study, it was found that using scrap $1.5 \%$ by weight improves the properties of the pressure and flexural strength properties of the composites. It was also observed that using scrap $2 \%$ by weight waste reduces the effects, when the shrinkage behavior was examined.
\end{abstract}

Keywords: Punching scrap, cementitious composite, glass fiber

\section{GíRiş}

Çimento bazlı kompozitlerde fiber kullanımın en önemli avantajları çekme dayanımını ve enerji yutma kapasitesini arttırmasıdır [1,2]. Kompozit yapı yüke maruz kaldığında, mikro çatlaklar açılıp yayılarak elastik olmayan deformasyonlara yol açmaktadır [3]. Kısa ve rastgele dağılmış fiberler kompozit yapılarda mikro çatlakların açılmasını ve yayılmasını engelleyici etki yapmaktadır [4].

Kompozitlerdeki fiber oranı kritik seviyeye kadar yükseltildikçe dayanım ve tokluk gibi mekanik özellikler iyileşmektedir. Ancak yüksek oranda kullanım kıvam kaybı ve topaklaşma gibi sorunlara da yol açabilmektedir. Bu nedenle kritik fiber oranının belirlenmesinin yanında, 
kompozit karışımların erken dönem özellikleri de dikkate alınmalıdır [5]. Çimento bazlı kompozit üretiminde de diğer üretim dallarında olduğu gibi bu faktörlerin değerlendirmesi büyük bir titizlikle gerçekleştirilmelidir.

Çimento bazlı kompozitler uygulamada birçok fiber türü ile güçlendirilmektedir. Günümüzde en yaygın olarak kullanılan fiber türü yüksek elastisite modülü malzeme özelliği ile çeliktir. Diğer yandan çelik fiberlerin korozyona karşı olumsuz etkisi ve ölü ağırlığı arttırıcı katkısı olumsuz anlamda değerlendirilmektedir [6]. Cam fiberler ise çimento bazlı kompozitlerde geniş olarak kullanılmaktadır. Gerçekleştirilen çalışmalara göre cam fiber eklenmesi, taze harcın işlenebilirliğini azaltmakta ve bu durum arrtılan fiber oranı ile dengelenerek, sertleşmiş kompozitin dayanımlarına olan olumsuz etkisi ortadan kaldırılmaya çalışılmaktadır [7,8]. Cam fiber takviyesinin çekme, darbe ve eğilme dayanımlarını arttırıcı etkisi birçok çalışma ile kanıtlanmıştır $[9,10]$

Zımba makinaları, otomotiv, elektrik, elektronik, kimyasal ve diğer yüksek verimli endüstriyel ürünlerdeki sac metal parçaların üretiminde yaygın olarak kullanılmaktadır. Sac metal endüstrisi giderek rekabetçi bir küresel pazarla karşı karşıyadır. Bu nedenle, bu pazarda rekabet edebilmek için daha uzun takım ömrü, daha yüksek strok oranları ve daha kaliteli parçalar elde etmek elzem hale gelmiştir. Sadece üretim girdilerinin optimizasyonu değil, üretim artıklarının değerlendirilmesi büyük önem taşımaktadır $[11,12]$.

İş parçasının kalitesi ve doğruluğu, takım tasarımı, zımba malzemesi özellikleri, delme koşulları ve özellikle zımba aşınması gibi birçok faktöre bağlı olarak değerlendirilir. Sac metal kalıplarında işlem sırasında ortaya çıkan artıkların mümkünse geri dönüşme sokulması, mümkün değilse başka alanlarda değerlendirilmesi üretim maliyetini azaltıcı ikincil faktörlerdendir.

Delme işleminde takım aşınması, iş parçalarının daha kötü geometrisi için önemli bir nedendir. Ayrıca, aşınma aynı zamanda delme-kesme kalıbının arıalanmasıyla sonuçlanır, bu da kalıp performansının beklenmedik bir şekilde sona ermesine ve delme işleminin artan üretim maliyetlerine neden olur. Delme işleminde, kesme boşluğu, delme hızı, takım geometrisi, yağlama ve malzemenin mekanik özellikleri gibi bazı faktörler, son iş parçası kesme kenarı geometrisinin kalitesini etkilemektedir [13]. Yüksek kalite de üretilen son ürünlere rağmen, zımba ile delme artıkların değerlendirilmesi büyük önem taşımaktadır.

Zımba artıklarının beton içerisinde güçlendirme elemanı olarak kullanılmasını hedefleyen çalışma sayısı literatürde çok sınırlıdır, Cam elyaf takviyeli çimento bazlı kompozitlerde kullanıma dair herhangi bir çalışma bulunmamaktadır. $\mathrm{Bu}$ çalışma ile zımba artıklarının değerlendirilmesi sağlanabileceği gibi cam elyaf takviyeli kompozitlerde kullanılmalarının önünün açılması düşünülmektedir.

\section{MALZEME VE METOD}

AISI 304 östenitik paslanmaz çelik delme artıkları bu çalışma kapsamında \%1, \%1,5 ve \%2 olmak üzere ağırlıça üç oranda kullanılmıştır. Çapları $5 \mathrm{~mm}$ (Şekil-1) ve $7 \mathrm{~mm}$ (Şekil-2), kalınlıkları 1,2 mm olan delme artıklarına ait kimyasal bileşim ve mekanik özellikler Tablo 1 ve Tablo 2 de sırasıyla sunulmuştur.

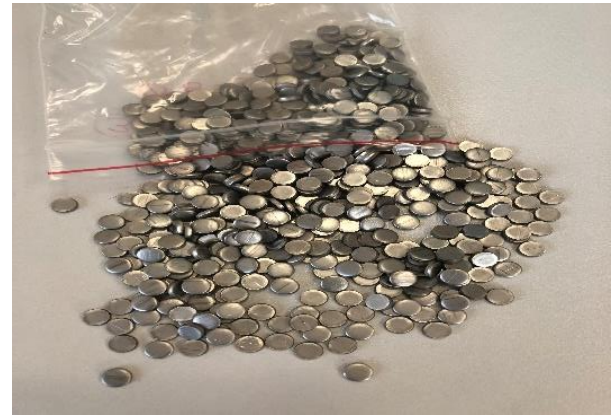

Şekil 1. 5 mm’ lik AISI 304 paslanmaz çelik delme artığ

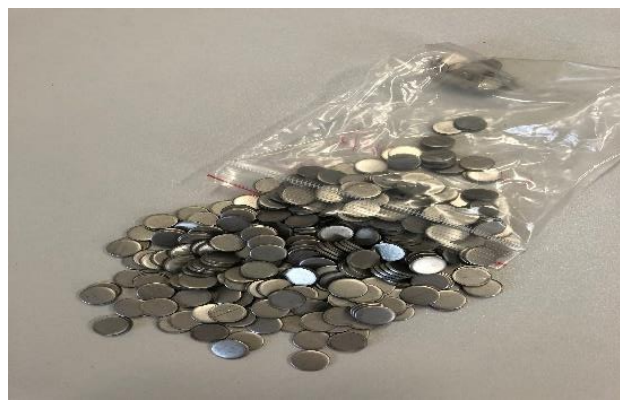

Şekil 2. 7 mm 'lik AISI 304 paslanmaz çelik delme artığı

Tablo 1. AISI 304 paslanmaz çelik kimyasal bileşimi

\begin{tabular}{|l|l|}
\hline Malzeme (\% wt.) & AISI 304 \\
\hline $\mathrm{C}$ & 0,58 \\
\hline $\mathrm{Mn}$ & 1,62 \\
\hline $\mathrm{Si}$ & 0,15 \\
\hline $\mathrm{Cr}$ & 19,06 \\
\hline $\mathrm{S}$ & 0,03 \\
\hline $\mathrm{P}$ & 0,09 \\
\hline $\mathrm{Ni}$ & 9,67 \\
\hline Denge / Fe & 68,81 \\
\hline
\end{tabular}

Tablo 2. AISI 304 paslanmaz çeliğin mekanik özellikleri

\begin{tabular}{|l|l|}
\hline Çekme Gerilmesi $\left(\mathrm{N} / \mathrm{mm}^{2}\right)$ & 505 \\
\hline Akma Gerilmesi $\left(\mathrm{N} / \mathrm{mm}^{2}\right)$ & 215 \\
\hline Sertlik (HRB) & 70 \\
\hline Yoğunluk $\left(\mathrm{gr} / \mathrm{cm}^{3}\right)$ & 8 \\
\hline
\end{tabular}

Bağlayıcı olarak CEM I 52.5 R tipi Portland çimentosu tercih edilmiştir. Çimentonun kimyasal ve fiziksel özellikleri Tablo 3'de verilmiştir. 
Tablo 3. CEM I 52.5 R çimentosunun kimyasal ve fiziksel özellikleri

\begin{tabular}{|l|l|}
\hline Kimyasal özellikler (\%) \\
\hline $\mathrm{SiO}_{2}$ & 21,6 \\
\hline $\mathrm{Al}_{2} \mathrm{O}_{3}$ & 4,03 \\
\hline $\mathrm{Fe}_{2} \mathrm{O}_{3}$ & 0,27 \\
\hline $\mathrm{CaO}$ & 65,6 \\
\hline $\mathrm{MgO}$ & 1,3 \\
\hline $\mathrm{Na}_{2} \mathrm{O}$ & 0,3 \\
\hline $\mathrm{K}_{2} \mathrm{O}$ & 0,35 \\
\hline $\mathrm{SO}_{3}$ & 3,30 \\
\hline $\mathrm{Serbest} \mathrm{CaO}_{\mathrm{K} 1 z d ı r m a ~ k a y b 1}$ & 1,60 \\
\hline Fiziksel özellikler & 3,2 \\
\hline Özgül Ağırlık & \\
\hline Özgül yüzey (cm $/$ /gr.) & 3,06 \\
\hline Beyazlık (\%) & 4600 \\
\hline & 85,5 \\
\hline
\end{tabular}

Alkali dayanımlı cam fiberler ağırlıkça \%3 oranında hazırlanan karıșımlara eklenmiştir. Kullanılan cam fiberlere ait olan malzeme özellikleri Tablo 4'deki gibidir.

Tablo 4. Alkali dayanımlı cam fiber özellikleri

\begin{tabular}{|l|l|}
\hline Eğilme dayanımı $(\mathrm{MPa})$ & $20-28$ \\
\hline Elastik limit $(\mathrm{MPa})$ & $7-11$ \\
\hline Basınç dayanımı $(\mathrm{MPa})$ & $50-80$ \\
\hline Elastisite modülü $(\mathrm{GPa})$ & $10-20$ \\
\hline Isıl iletkenlik $(\mathrm{W} / \mathrm{mK})$ & $0.034-0.04$ \\
\hline Yoğunluk $\left(\mathrm{kg} / \mathrm{cm}^{3}\right)$ & $1870-2100$ \\
\hline
\end{tabular}

Kompozit karışım dizaynı sırasında agrega olarak 80 ile 100 arasında AFS değerine sahip silis kumu tercih edilmiştir. Agregaya ait malzeme özellikleri Tablo 5'te sunulmuştur.

Tablo 5. Silis kumu özellikleri

\begin{tabular}{|l|l|}
\hline Fiziksel özellikler \\
\hline Özgül ağırlık $\left(\mathrm{t} / \mathrm{m}^{3}\right)$ & 2,69 \\
\hline Kil içeriği $(\%)$ & $0,6-0,8$ \\
\hline AFS değeri & 87,8 \\
\hline Kimyasal bileşim (\%) \\
\hline $\mathrm{SiO}_{2}$ & 98,55 \\
\hline $\mathrm{Fe}_{2} \mathrm{O}_{3}$ & 0,13 \\
\hline $\mathrm{MgO}$ & 0,03 \\
\hline $\mathrm{CaO}$ & 0,01 \\
\hline $\mathrm{K}_{2} \mathrm{O}$ & 0,09 \\
\hline $\mathrm{Na}_{2} \mathrm{O}$ & 0,02 \\
\hline $\mathrm{Al}_{2} \mathrm{O}_{3}$ & 1,11 \\
\hline
\end{tabular}

Polikarboksil bazlı 3. jenerasyon hiper akışkanlaştırıcı ve içme suyu bu çalışma kapsamında kullanılmıştır. Deneysel çalışmaya ait setler Tablo 6'da verilmiştir. Referans karışım silis kumu, çimento, cam fiber, su ve hiper akışkanlaştırıcıdan oluşmaktadır. Tüm karışımlarda 12 mm' lik cam fiberler ağırlıkça \%3 oranında sabit olarak kullanılmıştır. Cam fiberler ve zımba ile delme artıkları eklenmeden diğer bileşenler 5 dakika boyunca karıștırılmıștır. Fiber ve delme artıkları eklendikten sonra ise tekrar 2 dakika boyunca $250 \mathrm{dk} . / \mathrm{rpm}$ hızla karıştırılmıştır. İkinci karıştırmanın düşük hızda yapılmasının sebebi ise cam fiberlerin karıştırma esnasında kırılmasının engellenmesidir.

Tablo 6. Deney setleri

\begin{tabular}{|l|c|c|c|c|}
\hline $\begin{array}{c}\text { Döküm } \\
\text { nu. }\end{array}$ & $\begin{array}{c}\text { Cam Fiber } \\
\text { İçeriği }\end{array}$ & $\mathrm{S} / C ̧$ & $\begin{array}{c}\text { Delme } \\
\text { Artı̆̆ } 1 \\
\text { İçeriği } \\
(5 \mathrm{~mm})\end{array}$ & $\begin{array}{c}\text { Delme } \\
\text { Artığ1 } \\
\text { İçeriği } \\
(7 \mathrm{~mm})\end{array}$ \\
\hline $\mathrm{R}$ & $\% 3$ & 0,5 & - & - \\
\hline $\mathrm{K}_{51}$ & $\% 3$ & 0,5 & $\% 1$ & $\% 1$ \\
\hline $\mathrm{K}_{51.5}$ & $\% 3$ & 0,5 & $\% 1,5$ & $\% 1,5$ \\
\hline $\mathrm{K}_{52}$ & $\% 3$ & 0,5 & $\% 2$ & $\% 2$ \\
\hline $\mathrm{K}_{71}$ & $\% 3$ & 0,5 & $\% 1$ & $\% 1$ \\
\hline $\mathrm{K}_{71.5}$ & $\% 3$ & 0,5 & $\% 1,5$ & $\% 1,5$ \\
\hline $\mathrm{K}_{72}$ & $\% 3$ & 0,5 & $\% 2$ & $\% 2$ \\
\hline
\end{tabular}

Tablo 6'da görüldüğü gibi R referans numuneyi, K delme artığ1 katkılı numuneleri; $\mathrm{K}_{\mathrm{ab}}$ 'de ise a zımba çapını, b ise ağırlıkça karışma eklenen yüzdesini göstermektedir.

Basınç testleri için 40 x 40 x $40 \mathrm{~mm}$ boyutlarında küp kalıplar; eğilme testleri için ise $160 \times 40$ x $40 \mathrm{~mm}$ boyutlarında dikdörtgen prizması kalıplar tercih edilmiştir. Basınç ve eğilme testleri TS EN 1170-5 uyarınca 1,7 ve 28 günlük olarak gerçekleştirilmiştir. Yayılma testleri ise silindir bir aparat yardımıyla gerçekleştirilmiştir. Donma ve çözünme çevrimleri ise ASTM C 666 uyarınca yapılmıştır. Donma ve çözünme kabinindeki numunelerin yerleri belli aralıklarla değiștirilerek, test kabini içerisindeki tüm olumsuz koşullardan bütün numunelerin etkilenmesi sağlanmıştır. Büzülme değerleri ise lazer tabanlı büzülme test cihazı ile ilk 24 saate kaydedilmiştir. Su emme testleri ise 28 gün kür süresinin takiben 40 x 40 x 40 mm'lik numuneler üzerinde gerçekleştirilmiştir.

\section{BULGULAR VE TARTIŞMA}

Yayılma testi sonucu elde edilen ve taze haldeki kompozit karışıma ait değerler Şekil 3'de verilmiştir.

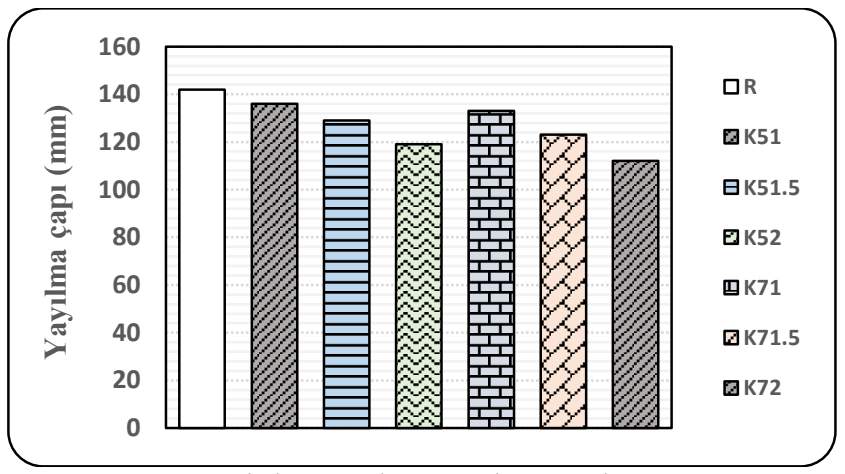

Şekil 3. Kompozit karışımları yayılma çapları

Gerçekleştirilen kıvam test sonuçlarına göre delme artığ çapı ve miktarı arttıkça yayılma çapları düşmüştür. Bu düşüşün karışımların işlenebilirliği üzerine negatif etkisi olmuştur. Bu durum artan delme atığı miktarının, fiberlerin 
ve delme artıklarının kompozit karışımı içerisindeki dengesiz ve düzensiz dağılmasına neden olması ile açıklanabilmektedir.

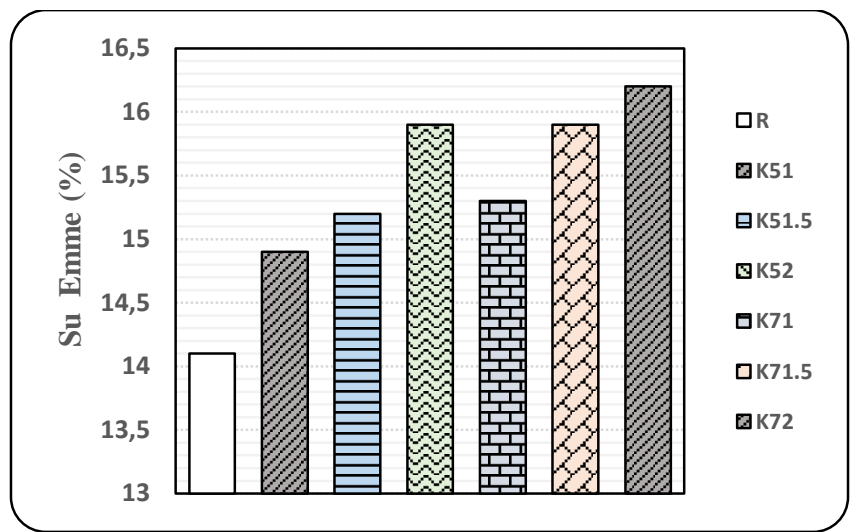

Şekil 4. Su emme test sonuçları

$\mathrm{Su}$ emme test sonuçları Şekil 4'de sunulmuştur. Bu test sonuçlarına göre delme artık çapının ve ağırlıkça içreğinin artması, marjinal olarak referans numuneye göre su emme miktarlarının da artmasına neden olmuştur. $\mathrm{K}_{72}$ numunesi $\% 16,2$ 'lik test sonucuyla en yüksek su emme değerine sahip olmuştur.

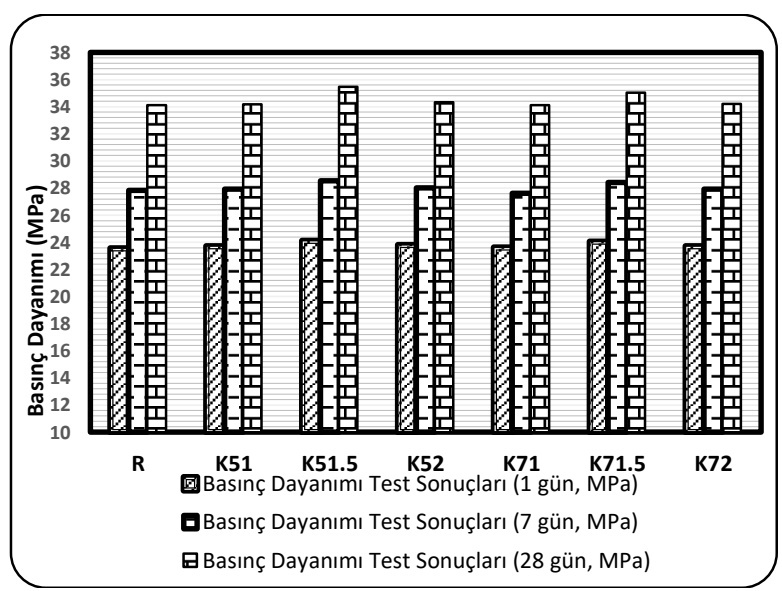

Şekil 5. Basınç dayanımı test sonuçları

1,7 ve 28 günlük basınç dayanımı test sonuçları Şekil 5'de verilmiştir. Test sonuçlarına göre zımba ile delme artığı eklenmesi kompozitlerin basınç altındaki etkisi altındaki davranışlarını biraz iyileştirmiștir. Özellikle $5 \mathrm{~mm}$ çapındaki ve ağırlıkça \% 1,5 delme artığına sahip karışım en iyi performansı göstermiştir. Ağırlıkça \%1,5'ten fazla delme artığı kullanılması, zımba ile delme artıklarının ve fiberlerinin kompozit karışımı içerisinde düzenli bir dağılım göstermesini engellemiş ve lokal topaklanmalara sebep olduğu düşünülmektedir. $\mathrm{Bu}$ sonuçlar taze durum testlerinden olan yayılma sonuçları ile de uyumludur. Bu durum basınç altında daha fazla gerilmenin matris üzerinde odaklanmasını sağlamaktadır.

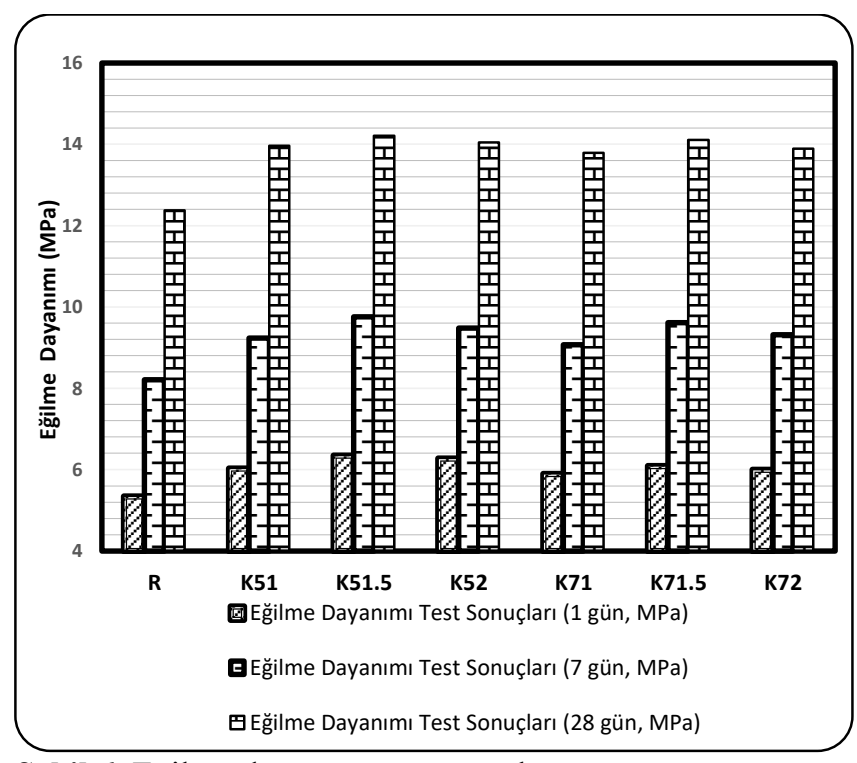

Şekil 6. Eğilme dayanımı test sonuçları

Eğilme test sonuçları Şekil 6'da görüldüğü gibidir. Zımba ile delme artıklarının eklenmesi eğilme dayanımlarını ciddi derecede arttırmıştır. En büyük eğilme dayanımı değeri 14,21 MPa'lik test sonucuyla $\mathrm{K}_{51.5}$ numunesiyle elde edilmiştir. Eğilme test sonuçları, karışımların \%1,5'luk delme artığı içeriğini aşmasıyla düşüş eğilimi göstermiştir. Test sonuçları delme atıklarının cam fiber ile birlikte kullanılmasının eğilme gerilmelerine karşı kompozitin özelliklerini geliştirdiği göstermiştir.

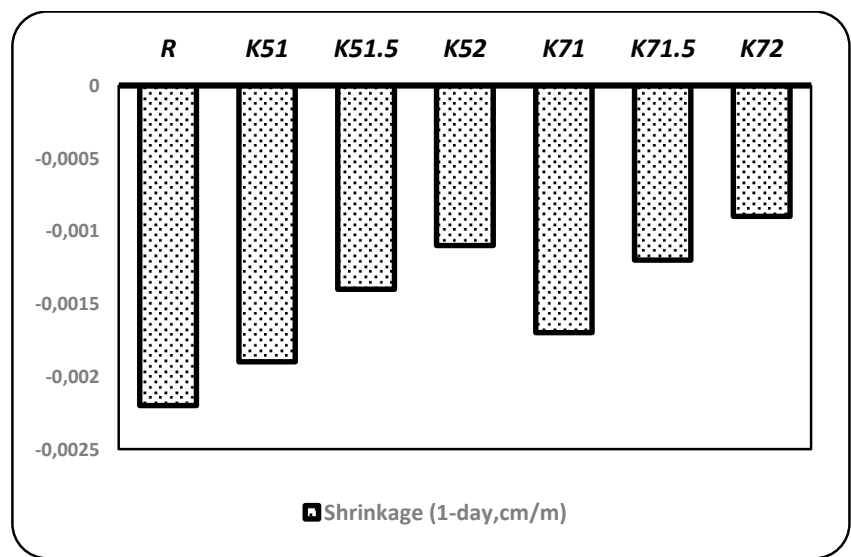

Şekil 7. Büzülme testi sonuçları

Büzülme test sonuçları Şekil 7'de verilmiştir. Referans numune ile karşılaştırıldığında, zımba ile delme artık ilavesinin kompozitlerin büzülme etkisi altındaki davranışını belirli limitler dahilinde iyileştirdiği gözlemlenmiştir. Ayrıca, endüstriyel delme artığı içeriğ arttıkça daha iyi sonuçların elde edildiği görülmüştür. 


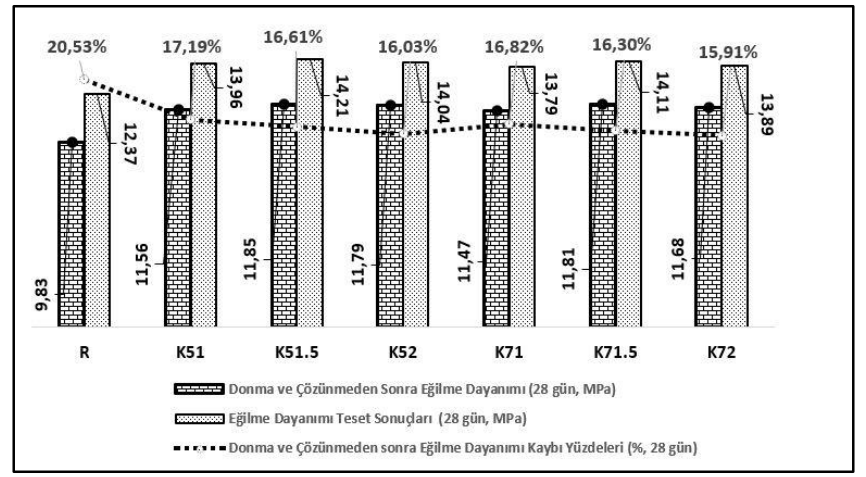

Şekil 8. Donma ve çözünme çevrimleri sonucu eğilme dayanımı kaybı

Donma ve çözünme çevrimleri sonucunda elde edilen eğilme test sonuçları Şekil 8'de verilmiştir. Donma çözünme çevrimleri sonrasında, en az etkilenen numuneler, endüstriyel delme atık oranı ağırlıkça \%2 içeriğine sahip olanlar olarak elde edilmiştir. Zımba ile delme artığ içeriği olan kompozitler, referans numuneye göre daha iyi performans göstermişlerdir.

\section{SONUÇLAR}

$\mathrm{Bu}$ çalışma kapsamında endüstriyel zımba ile delme artıklarının, cam elyaf takviyeli çimento bazlı kompozitlerin mekanik davranışları üzerine etkisi incelenmiştir. Gerçekleştirilen deneysel çalışmalardan aşağıdaki sonuçlar çıkarılmıştır:

- Endüstriyel zımba ile delme artıklarının, çalışma kapsamında incelenen kompozitlerin muhtevasına eklenmesi su emme değerlerinin artmasına sebep olmuştur. $\mathrm{Bu}$ nedenle orta ve uzun vadede durabilite problemlerine karşı önlem alınması sonucu ortaya çıkmıştır.

- Endüstriyel delme artıklarının eğilme dayanımına ciddi derecede katkı sağladığı tespit edilmiştir.

- Kompozitlerin basınç dayanımlarının ise gözle görünür derecede iyileşmesi delme artıkları ile sağlanmıştır.

- Büzülme etkisi altındaki kompozit davranış1, delme artıkları ile belirli limitler dahilinde iyileştirilmiştir.

- Donma ve çözünme etkisine karşı en uygun zımba ile delme artığı oranı ağırlıkça \%2 olarak tespit edilmiştir.

- Delme artıklarının değerlendirilmesi sağlanarak, atık olması halindeki çevresel olumsuz etkileri azaltılmasına örnek teşkil etmiştir.

\section{KAYNAKÇA}

[1] Bentur, A., and S. Mindess. Fibre reinforced cementitious composites. CRC Press, 2014.

[2] Halpin, J. C. Primer on Composite Materials Analysis, (Revised). Routledge, 2017.

[3] Kasagani, H., and C. B. K. Rao. "Effect of graded fibers on stress strain behaviour of Glass Fiber Reinforced Concrete in tension." Construction and Building Materials 183 (2018): 592-604.

[4] Betterman, L. R., C. Ouyang, and S. P. Shah. "Fibermatrix interaction in microfiber-reinforced mortar." Advanced Cement Based Materials 2.2 (1995): 53-61.

[5] Song, P. S., and S. Hwang. "Mechanical properties of high-strength steel fiber-reinforced concrete." Construction and Building Materials 18.9 (2004): 669-673.

[6] Neville,A.M., Brooks, J.J., (1987) Concrete Technology Longman Scientific and Technical, p.285.

[7] Dehghan, A., Karl P., and A. Shvarzman. Recycled glass fiber reinforced polymer additions to Portland cement concrete. Construction and Building Materials 146, 2017: 238-250.

[8] Sathanandam, T., Low carbon building: Experimental insight on the use of fly ash and glass fibre for making geopolymer concrete. Sustainable Environment Research 27.3 (2017): 146-153.

[9] Mastali, M., A. Dalvand, and A. R. Sattarifard. The impact resistance and mechanical properties of reinforced self-compacting concrete with recycled glass fibre reinforced polymers. Journal of Cleaner Production, 124 2016: 312-324.

[10] Vijayalakshmi, M., and A. S. S. Sekar. Strength and durability properties of concrete made with granite industry waste. Construction and Building Materials 46, 2013: 1-7.

[11] Marcondes, P.V.D., Eto, A.M., P.A.C. Beltrăo, P.C. Borges, A smart stamping tool for punching and broaching combination, Journal of Materials Processing Technology,206(2008) 184-193.

[12] Hatanaka N., Yamaguchi K., Takakura N. and Iizuka T. Simulation of sheared edge formation process in blanking of sheet metals, Journal of Materials Processing Technology, 140,2003: 628-634.

[13] Yağır, M. O., \& Mete, O. H., Proses azaltıcı kalıp tasarımında endüstriyel bir ürünün delme ve kılavuz çekme işlemlerinin nümerik model analizi. Sakarya University Journal of Science, 21(2), 2017,131-140. 